\title{
Estrogen regulation of vascular endothelial growth factor in breast cancer in vitro and in vivo: the role of estrogen receptor $\alpha$ and c-Myc
}

\author{
Maya Dadiani*, Dalia Seger*, Tamar Kreizman, Daria Badikhi, \\ Raanan Margalit, Raya Eilam and Hadassa Degani
}

Department of Biological Regulation, Weizmann Institute of Science, Rehovot 76100, Israel

(Correspondence should be addressed to H Degani; Email: hadassa.degani@weizmann.ac.il)

*(M Dadiani and D Seger contributed equally to this work)

\begin{abstract}
The role of c-Myc in estrogen regulation of vascular endothelial growth factor (VEGF) and of the vasculature function has been investigated in breast cancer cells and tumors. The studies were performed on MCF7 wild-type cells and MCF7-35im clone, stably transfected with an inducible $c-M y c$ gene. In vitro and ex vivo methods for investigating molecular events were integrated with in vivo magnetic resonance imaging of the vascular function. The results showed that the c-Myc upregulation by estrogen is necessary for the transient induction of VEGF transcription; however, overexpression of c-Myc alone is not sufficient for this induction. Furthermore, both c-Myc and the activated estrogen receptor $\alpha(E R \alpha)$ were shown to co-bind the VEGF promoter in close proximity, indicating a novel mechanism for estrogen regulation of VEGF. Studies of long-term estrogen treatment and overexpression of c-Myc alone demonstrated regulation of stable VEGF expression levels in vitro and in vivo, maintaining steady vascular permeability in tumors. However, withdrawal of estrogen from the tumors resulted in increased VEGF and elevated vascular permeability, presumably due to hypoxic conditions that were found to dominate VEGF overexpression in cultured cells. This work revealed a cooperative role for $\mathrm{ER} \alpha$ and c-Myc in estrogen regulation of VEGF and the ability of c-Myc to partially mimic estrogen regulation of angiogenesis. It also illuminated the differences in estrogen regulation of VEGF during transient and long-term sustained treatments and under different microenvironmental conditions, providing a complementary picture of the in vitro and in vivo results.
\end{abstract}

Endocrine-Related Cancer (2009) 16 819-834

\section{Introduction}

Tumor angiogenesis is a highly complex process, involving various activating and suppressive factors, including the family members of vascular endothelial growth factor (VEGF; Yancopoulos et al. 2000, Dvorak 2002, Hicklin \& Ellis 2005). VEGF is a highly specific mitogen for vascular endothelial cells, inducing proliferation and migration of these cells and forming new capillaries by sprouting. VEGF is also known to augment capillary permeability and, therefore, was originally termed vascular permeability factor (Dvorak 2002). The expression of VEGF is regulated by a variety of effectors, including hypoxiainduced factors, growth factors, hormones, oncogenes, and cytokines (Loureiro \& D'Amore 2005). Although evidence has been accumulating concerning estrogen regulation of VEGF in breast cancer, the findings are still controversial and the underlying mechanism remains unclear (Hyder 2006).

To better understand how estrogen regulates VEGF in breast cancer, it is necessary to elucidate the cascade of molecular events downstream of the estrogen receptors $\alpha$ and $\beta$ (ER $\alpha$ and $E R \beta)$. Both receptors mediate the activity of estrogen in a variety of normal 
and malignant cells and tissues, with the levels of the two receptors being highly diverse (Nilsson et al. 2001). Most breast cancers express both ERs; however, $\mathrm{ER} \alpha$ appears to be the predominant form in breast tumors associated with estrogenic stimulation of gene expression and cell proliferation (Jarvinen et al. 2000, Kurebayashi et al. 2000, Palmieri et al. 2002), whereas ER $\beta$ appears to exhibit growth suppressive effects (Frasor et al. 2003, Strom et al. 2004).

One likely candidate that is stimulated by estrogen and may serve as a 'master key' regulator in breast cancer is the $c-M y c$ proto-oncogene that encodes the c-Myc transcription factor. Estrogen has been shown to activate c-Myc expression in ER $\alpha$-positive human breast cancer cells through its enhanced transcription (Dubik \& Shiu 1988, 1992). Recent extensive studies have clearly demonstrated the predominance of c-Myc as a target of estrogen action and its role as a mediator of estrogen effects on cell growth (Musgrove et al. 2008). Furthermore, inducible expression of c-Myc was shown to be sufficient for overriding antiestrogeninduced cell growth arrest (Prall et al. 1998) and to partially restore proliferation of cells maintained in estrogen free medium (Venditti et al. 2002). These results indicated that induction of c-Myc expression is sufficient to confer resistance to antiestrogen treatment.

Activation of c-Myc alone is known to promote cell growth and proliferation, inhibit differentiation, and sensitize cells to apoptosis (Dang et al. 1999). Indeed, overexpression of c-Myc is often associated with aggressive, poorly differentiated tumors (Liao \& Dickson 2000, Pelengaris et al. 2002). Recent studies also indicated that VEGF expression levels are also controlled by c-Myc (Barr et al. 2000, Knies-Bamforth et al. 2004) and that c-Myc is essential for angiogenesis (Baudino et al. 2002). Other studies have revealed that c-Myc plays a central role in the angiogenic switch in tumors (Knies-Bamforth et al. 2004, Shchors et al. 2006).

The well-established estrogen regulation of c-Myc via $\mathrm{ER} \alpha$, and the role of $\mathrm{c}-\mathrm{Myc}$ in angiogenesis led to the hypothesize that $\mathrm{c}-\mathrm{Myc}$ mediates the estrogenic regulation of VEGF in breast cancer. In the present study, we tested this hypothesis in vitro and in vivo and characterized estrogen regulation of VEGF under different protocols of estrogen treatment and varying environmental conditions. In addition, we examined whether c-Myc alone can also regulate VEGF and vascular function in breast cancer. In order to differentiate between estrogen upregulation of c-Myc through ER $\alpha$ and induction of c-Myc alone, we concentrated on investigating MCF7 human breast cells, stably transfected with a tetracycline
(Tet)-inducible c-Myc gene - MCF7-35im (Venditti et al. 2002). We further confirmed the in vitro results using MCF7 wild-type (WT) cells. Taken together, our studies revealed a cooperative involvement of $\mathrm{ER} \alpha$ and c-Myc in mediating estrogen regulation of VEGF expression and function as a permeability factor in breast cancer cells and tumors. They also show that long-term overexpression of c-Myc alone can partially mimic estrogen regulation of VEGF, suggesting an additional mechanism for antiestrogen resistance.

\section{Materials and methods}

\section{Cells}

MCF7-WT human breast cancer cells were routinely cultured in DMEM supplemented with $6 \%$ fetal bovine serum (FBS), $4 \mathrm{mM}$ glutamine, and $0.1 \%$ combined antibiotics. Human breast cancer MCF7-35im cloned cells were kindly provided by Dr Robert Shiu, University of Manitoba, Winnipeg, Canada. The stability of the Tet inducible $c-M y c$ gene in these cells was confirmed following the report of Venditti et al. (2002). These cells were routinely cultivated in DMEM supplemented with 10\% FBS, 4 mM glutamine and $0.1 \%$ combined antibiotics. For hormonal manipulation experiments the above described cells (70\% confluent) were initially primed twice in a medium containing phenol red-free DMEM supplemented with dextran-coated charcoal-stripped FBS (DCC; 6\% for MCF7-WT and 10\% for MCF7-35im), $4 \mathrm{mM}$ glutamine and $0.1 \%$ antibiotics. Hereinafter, we use the abbreviation DCC for describing this estrogen-free medium.

\section{Treatments of cells and protein analysis}

Cells cultivated for hormonal manipulation as described above in DCC medium were treated with $17 \beta$-estradiol ( $\mathrm{E}_{2} ;$ Sigma-Aldrich), prepared from an aqueous stock solution containing $0.1 \%$ ethanol. Upregulation of c-Myc transcription was induced in MCF7-35im cells incubated for $16 \mathrm{~h}$ in DCC containing Tet (doxocycline, $2.5 \mu \mathrm{g} / \mathrm{ml}$; SigmaAldrich) prior to further treatments.

In the long-term $\mathrm{E}_{2}$ treatment and withdrawal experiments, cells were cultured in DCC medium supplemented with $30 \mathrm{nM} \mathrm{E}_{2}$ for 2 days. Then, the cells were divided into three groups: 1) withdrawal of $E_{2}$ and cultivation in DCC (EWD), 2) continue DCC medium supplemented with $E_{2}$, and 3) withdrawal of $E_{2}$ and addition of Tet. The cells in each group were harvested and analyzed after 3, 4, 5, and 7 days of treatment. 
Hypoxia-induced changes were investigated in cells cultivated for 2 days in DCC supplemented with $\mathrm{E}_{2}$ $(30 \mathrm{nM})$. Then, the cells were divided into three groups: EWD; $\mathrm{E}_{2}$; and Tet, and were cultivated for additional 4 days. The cells in each group were incubated for $14 \mathrm{~h}$ before the harvest under hypoxic conditions in an anaerobic jar containing Anaerocult A filter (Merck), or under normoxic conditions.

Total protein was extracted by incubation of cells in RIPA lysis buffer supplemented with fresh dithiothreitol, for $15 \mathrm{~min}$. After centrifugation the soluble fraction was collected. Samples were resolvedon 10\% SDS-polyacrylamide gels, and were then analyzed by western blot. Quantitation of the gels was performed relative to a reference gene. Antibodies for western blot were themouse anti-human c-Myc (clone 9E10, sc-40; Santa Cruz Biotechnology, Santa Cruz, CA, USA), mouse anti-human ER $\alpha$ antibody (clone 6F11; Novocastra Laboratories, Newcastle, UK), chicken polyclonal to ER $\beta$ (ab14021, Abcam, Cambridge, UK), and anti- $\alpha$-tubulin (clone DM-1A, Sigma-Aldrich, St Louis, MO, USA) as a reference for loading.

\section{RT-PCR}

Total RNA was isolated using the Versagene RNA cell kit $\left(5^{\prime}\right.$, former Gentra Systems, Minneapolis, MN, USA). RNAwas quantified by u.v. absorption using a Nanodrop ND-1000 spectrophotometer (Nanodrop Thermoscientific, Wilmington, DE, USA). cDNA was synthesized with oligo(dT) primers using a Dynamo cDNA synthesis kit (Finnzymes, Espoo, Finland). Real time (RT)-PCR was performed using the following primers, specific to VEGF-165: sense, 5'CACCAAGGCCAGCACATAGGA3'; anti-sense, 5'AGGCCCACAGGGATTTTCTTGT3'. For the control housekeeping gene, we used the $\beta 2$ microglobulin: sense, 5'ATTCAGGTTTACTCACGTCATCCA3 ${ }^{\prime}$; anti-sense, 5'GAGATAGAAAGACCAGTCCTT$\mathrm{GC}^{\prime}$. Quantitation of gels was performed relative to the reference gene.

\section{SiRNA}

Validated double-stranded siRNA oligonucleotidesand reagents were purchased from Dharmacon Research (Thermo Fisher Scientific, Lafayette, CO, USA) (SMARTpool siRNA reagent, Dharmacon Catalog \#M-003282-04 for c-Myc and \#L-003402 for ER $\beta$ ). The siRNAs were assessed for their ability to downregulate the specific protein expression, as compared with a supplied control siRNA. Cells were transfected using DharmaFECT 4 transfection reagent
(Dharmacon) for $48 \mathrm{~h}$ according to the procedure provided by the manufacturer. On the following day, the transfected cells were treated for $6 \mathrm{~h}$ in $\mathrm{E}_{2^{-}}$ containing medium or in DCC medium and then collected and analyzed.

\section{Chromatin immunoprecipitation assay}

Chromatin immunoprecipitation (ChIP) and ChIP re-immunoprecipitation assays were performed following the detailed protocol by Shang et al. (2000). Immunoprecipitation was performed with specific primary antibodies (anti-human c-Myc monoclonal antibody (clone 9E10, Santa Cruz Biotechnology) or anti-human ER monoclonal antibody (MAB447, Chemicon, Billerica, MA, USA) bound to Protein $G$ plus agarose beads (Santa Cruz Biotechnology). The association of $\mathrm{c}-\mathrm{Myc}$ and $\mathrm{ER} \alpha$ with the VEGF was measured by PCR, using specific primers amplifying a 500 bp DNA fragment from the immunoprecipitated DNA template (VEGF promoter forward primer: 5'GGAAATTGCTGCATTCCCATTC $^{\prime}$ and VEGF promoter reverse primer: 5'GGGCCTGCGTGATGATTCAAA3 ${ }^{\prime}$ ).

\section{Tumors}

All animal procedures were approved by the Institutional Animal Care and Use Committee of the Weizmann Institute of Science. Female immunodeficient mice (CD1-Nude), 6 weeks old, were obtained from the Weizmann Institute colony. One to 2 weeks later, the mice were ovariectomized and $E_{2}$ pellets $(0.72 \mathrm{mg} /$ pellet, 60 day release time; Innovative Research of America, Sarasota, FL, USA) were implanted underneath the back skin. Three days later, MCF7-35im cells were inoculated into the mammary fat pad ( $10^{7}$ cells in $\left.0.2-0.3 \mathrm{ml} \mathrm{PBS}\right)$. On day $23-25$ after inoculation the mice were randomly divided into three groups and were subjected to the following treatments: 1) continued $\mathrm{E}_{2}$ treatment through release from the originally implanted $\mathrm{E}_{2}$-pellets $\left.(n=8), 2\right)$ EWD achieved by surgically removing the $E_{2}$ pellet from the back skin by a minimal cut $(n=8)$, and 3) $\mathrm{E}_{2}$ withdrawal and Tet induction of c-Myc expression $(n=6)$. The Tet induction in the third group was achieved by supplementing the drinking water with $500 \mathrm{mg} / \mathrm{l} \mathrm{Tet} \mathrm{(Tevacycline,} \mathrm{Teva,} \mathrm{Petach} \mathrm{Tikva,} \mathrm{Israel)}$ and $30 \mathrm{~g} / \mathrm{l}$ sucrose, maintaining this solution in lightprotected bottles. After 2 days of adjustment of the mice to the various treatments, the tumors were sequentially scanned by magnetic resonance imaging (MRI), each 1-4 times within 20 days of continuous treatment. 


\section{Dynamic contrast-enhanced MRI}

Images were acquired with a $4.7 \mathrm{~T}$ Biospec spectrometer (Bruker Biospin, Rheinstetten, Germany) equipped with a ${ }^{1} \mathrm{H}$ radiofrequency coil. The mice were anesthetized by inhaling $1 \%$ isofluorane (Medeva Pharmaceuticals, Rochester, PA, USA) in an $\mathrm{O}_{2}: \mathrm{N}_{2} \mathrm{O}$ (3:7) mixture, applied through a nose cone. Initially, to define the size and gross morphology (i.e. necrosis) of the tumors, a multi-slice RARE $\mathrm{T}_{2}$-weighted sequence was recorded (TE/TR: 80/3193 ms). Subsequently, a dynamic experiment was conducted consisting of recording a pre-contrast and 30 post contrast, $\mathrm{T}_{1}$-weighted, three-dimensional gradient-echo images (TE/TR 4.3/18.3 ms; flip angle $30^{\circ} \mathrm{C}$; matrix, 256 $\times 128 \times 16$; FOV, $4 \times 4 \times 1.9 \mathrm{~mm}^{3}$ ), each for $37 \mathrm{~s}$. The contrast agent gadolinium diethylenetriaminepentaacetate (Gd-DTPA), (Magnevist, Schering, Berlin, Germany) was injected instantaneously to the tail vein at a dose of $0.4 \mathrm{mmol} / \mathrm{kg}$ body weight.

The dynamic datasets were analyzed pixel-by-pixel according to a physiological model, as previously described (Furman-Haran et al. 1997, Tofts 1997). Image analysis yielded the influx transcapillary transfer constants $K^{\text {trans }}$, which is the volume transfer constant between blood plasma and the interstitial space, and the efflux transfer rate constant between the interstitial space and blood plasma, $k_{\text {ep }}$. Both the transfer constants are predominantly determined by the product of vascular permeability and vascular surface area; the efflux transfer constant is also inversely proportional to the extracellular volume fraction (Tofts et al. 1999).

\section{Immunohistochemistry}

The anesthetized mice were perfused with saline prior to the removal of the tumors. The removed tumors were stained with color (The Davidson Marking System, Bradley Products, Bloomington, MN, USA) to indicate orientation with reference to the MRI image. Tumors were fixed by submersion in $1 \%$ formaldehyde for 24-48 $\mathrm{h}$ and then embedded in paraffin and sectioned parallel to the plane of the MR images ( $4 \mu \mathrm{m}$ slices for histological and immunostaining studies and $7 \mu \mathrm{m}$ for in situ hybridizations). The slices were stained with hematoxylin-eosin or by immunostaining with anti-ER antibody (6f11, Novocastra) or with anti-VEGF polyclonal antibody (sc-152, Santa Cruz Biotechnology), as well as for CD31 (MEC13.3, BD Pharmingen, Franklin Lakes, NJ, USA). Details of immunostaining are described in the supplementary material. All negative controls (without the primary antibody) did not show staining. Sectioned stained for $\mathrm{ER} \alpha$ and VEGF were graded in viable areas of the tumors, in six different tumors of each group, using three levels, of 1, 2 or 3 (from low to high staining) according to the staining intensity. Vessels' density was quantified by calculating the percentage of the area stained for CD31, using Image-Pro Plus 4.5 software (Media Cybernetics, Bethesda, MD, USA).

\section{Statistical analysis}

Statistical significances between the results of various treatments relative to those obtained in untreated cells cultivated in DCC medium (western blots and RT-PCR results) were calculated using Student's $t$-test. The values of the transcapillary transfer constants derived from analysis of the MRI datasets showed a skewed distribution around the mean; therefore, these values are presented as median \pm s.E.M., of each group of tumors, with a box chart determined by the 25 th and 75 th percentiles. Statistical differences between the transcapillary transfer constants were analyzed by ANOVA, together with Dunnet's multiple comparison tests.

\section{Results}

\section{Estrogen transient induction of VEGF and c-Myc}

$\mathrm{E}_{2}$ treatment of MCF7 WT and clone 35im cells, initially cultivated in DCC medium, induced a transient upregulation of c-Myc and VEGF-165 mRNA (hereinafter VEGF mRNA) and a concomitant transient reduction in ER $\alpha$ (Fig. 1). The level of VEGF mRNA increased within $1-2 \mathrm{~h}$ after $\mathrm{E}_{2}$ treatment, reaching a maximum at about $2-6 \mathrm{~h}$, and declining at $24 \mathrm{~h}$. A similar transient induction was found for a range of $\mathrm{E}_{2}$ concentrations (1-30 nM), confirming earlier reports of $E_{2}$ induction of VEGF in various human breast cancer cells (Ruohola et al. 1999, Maity et al. 2001, Buteau-Lozano et al. 2002, Stoner et al. 2004).

The induction of c-Myc by $E_{2}$ exhibited a time course that correlated with the transient $\mathrm{E}_{2}$-induced increase in VEGF mRNA levels in the cells (Fig. 1B). In parallel, ER $\alpha$ protein level gradually declined within $24 \mathrm{~h}$ of $\mathrm{E}_{2}$ treatment due to enhanced degradation, known to occur upon $\mathrm{E}_{2}$ signaling (Reid et al. 2003; Fig. 1C).

Treatment with the pure ER $\alpha$ antagonist ICI 172870 alone (fulvestrant, $3 \mu \mathrm{M}$ ) did not affect VEGF mRNA and c-Myc levels but reduced ER $\alpha$ level, in agreement with previously reported studies in these cells (Ruohola et al. 1999, Takei et al. 2002, Venditti et al. 2002, Long \& Nephew 2006).

To check whether ER $\beta$ receptor has a role in this pathway, we knocked down ER $\beta$ by specific siRNA in 

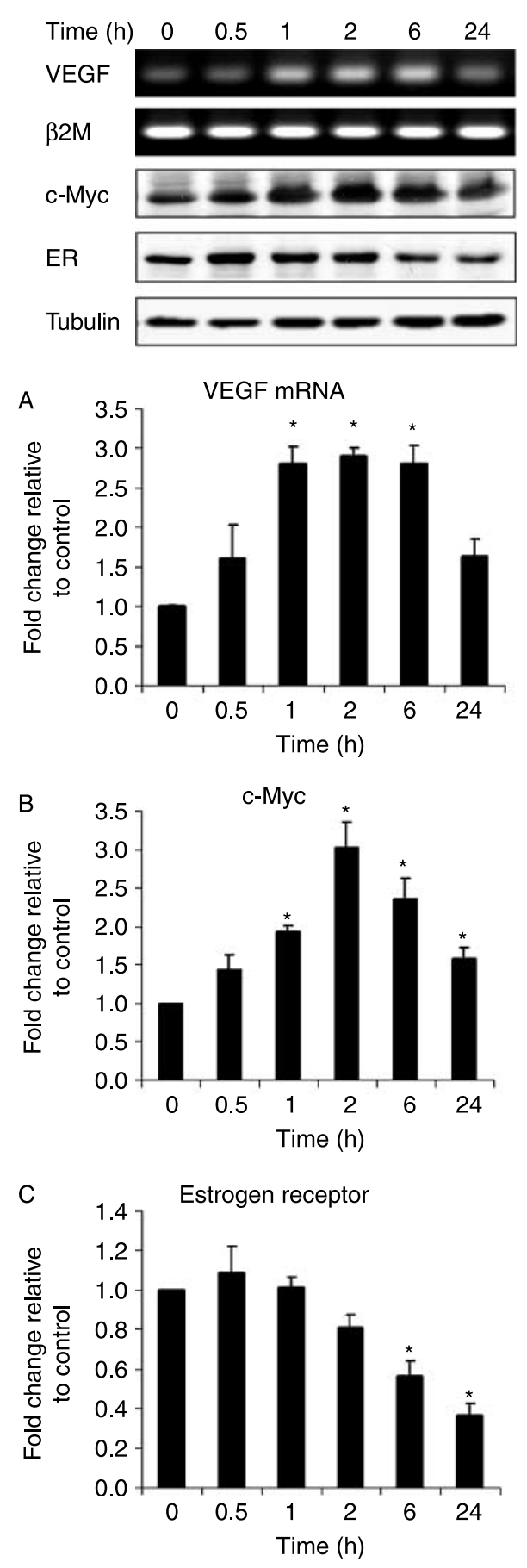

Figure 1 Transient estrogen regulation of VEGF-165, c-Myc and $E R \alpha$ in MCF7-35im cells in vitro. (A) $E_{2^{-}}(30 \mathrm{nM})$ induced VEGF mRNA expression at various time intervals, as indicated, determined by RT-PCR. (B) Estrogen-induced cMyc protein expression levels. The levels were determined by western blot analysis of the same samples as in (A). (C) Estrogen-induced $\mathrm{ER} \alpha$ degradation. The levels were determined by western blots analysis of the same samples as in (A). Results are presented as mean \pm S.E.M. (3-8 repetitions) fold change relative to those obtained in $E_{2}$-free medium at time zero. ${ }^{*} P<0.05$. both MCF7 and clone MCF7-35im cells. Reduction in the level of ER $\beta$ in siRNA treated cells (20-50\%) did not show a significant change in estrogen induction of VEGF mRNA, neither in c-Myc upregulation and ER $\alpha$ downregulation as compared with control siRNA cells (data not shown). Hence, it appears that estrogen regulation of VEGF in ER-positive cells that naturally express low levels of ER $\beta$ is predominantly mediated through $E R \alpha$, and the effect of $E R \beta$ is negligible.

It was previously shown that $\mathrm{E}_{2}$ induction of VEGF mRNA in MCF7 cells is followed by induction of VEGF protein accumulation (Ruohola et al. 1999, Maity et al. 2001, Buteau-Lozano et al. 2002). As a result of VEGF secretion and fast diffusion into the culture medium, and the high fraction of medium relative to the intracellular volume, the time course of VEGF level in the medium is slow, reaching peak level $\sim 24 \mathrm{~h}$ after treatment initiation. This slow time course reflects VEGF accumulation rather than production and lags behind the time courses of $E_{2}$-induced proteins that remained in the intracellular compartment. We, therefore, concentrated in the following experiments on characterizing the intracellular mRNA expression of VEGF.

We next examined whether c-Myc-induction by $\mathrm{E}_{2}$ is necessary for VEGF stimulation using a small interfering RNA (siRNA) for c-Myc. A significant reduction in c-Myc level was shown to occur in cells transfected with siRNA for c-Myc as compared with the corresponding control siRNA transfected cells in both DCC medium and in $\mathrm{E}_{2}$-supplemented medium (Fig. 2A). Induction of VEGF mRNA by $E_{2}$ was abolished in the c-Myc siRNA transfected cells as compared with the control siRNA transfected cells (Fig. 2B), although estrogen activation of ER $\alpha$ clearly occurred in control and c-Myc inhibited cells as shown by the massive reduction in ER $\alpha$ (blots in Fig. 2A). Similar experiments with MCF7-WT cells transfected with the siRNA for c-Myc yielded comparable results (not shown) indicating clearly that c-Myc plays a critical role in mediating the transient $E_{2}$ regulation of VEGF mRNA in MCF7 cells.

In order to find out whether high levels of c-Myc alone are sufficient to reproduce the $E_{2}$ induced transient induction of VEGF overexpression, MCF7$35 \mathrm{im}$ cells were treated with Tet. The level of c-Myc in the Tet-induced cells reached 4-fold higher levels than in cells cultivated in Tet-free, DCC medium, and was similar to the levels in $\mathrm{E}_{2}$ treated cells $(6 \mathrm{~h})$ and in Tet $+\mathrm{E}_{2}$ treated cells (Fig. 2C). However, the $16 \mathrm{~h}$ overexpression of c-Myc alone did not stimulate VEGF mRNA levels, as was seen in response to $E_{2}$ treatment $(6 \mathrm{~h})$, and Tet $+\mathrm{E}_{2}$ (6 h; Fig. 2D). These results indicate that the presence of high level of c-Myc alone for $\sim 16 \mathrm{~h}$ is not sufficient for inducing VEGF mRNA 
A

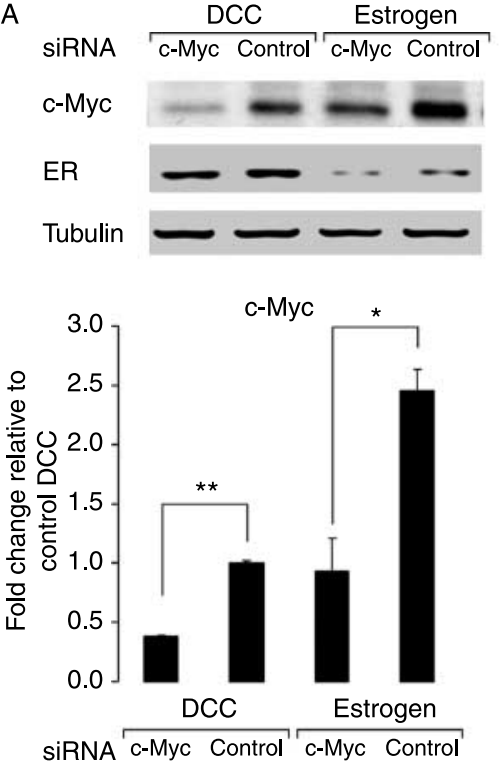

C
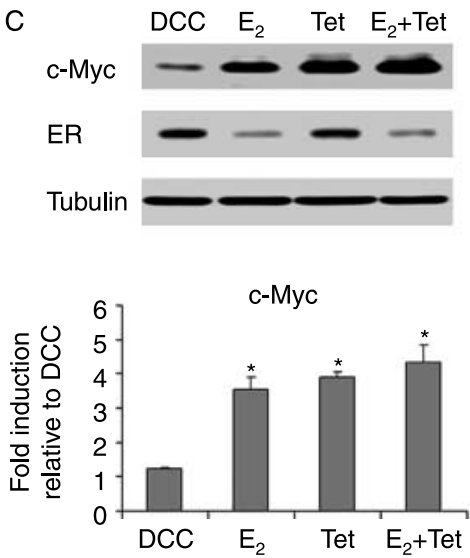
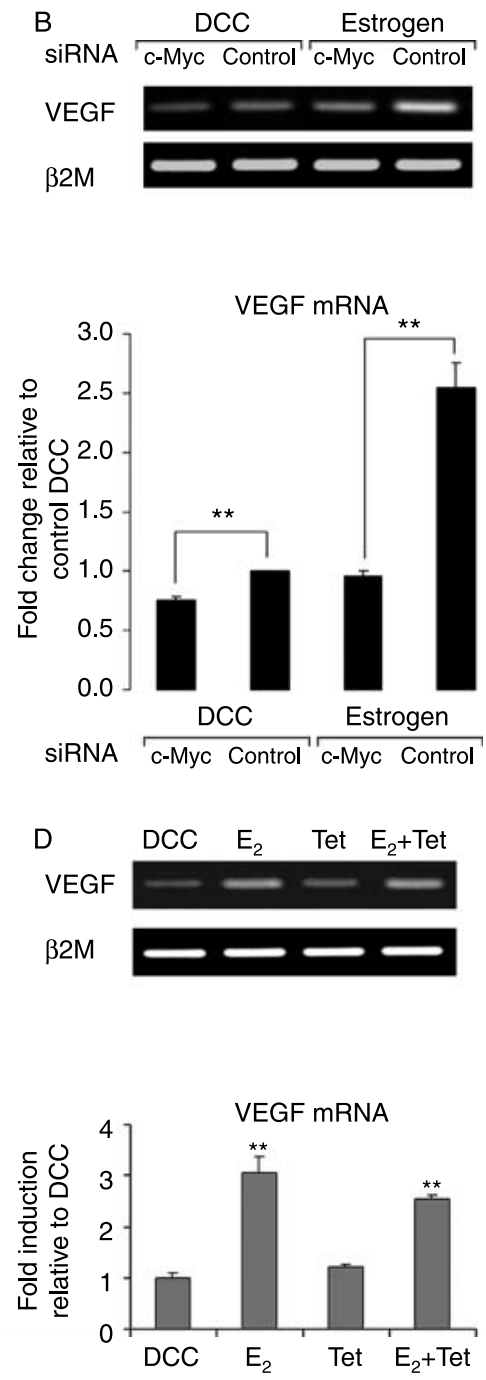

Figure 2 Estrogen-induction of VEGF in MCF7-35im cells transfected with siRNA for c-Myc (A and B) or overexpressing c-Myc $(C$ and $D)$. (A) Protein expression levels of $c-M y c$ in cells transfected with either siRNA for $c-M y c$ or control siRNA and cultivated for $6 \mathrm{~h}$ in $\mathrm{E}_{2}$-free medium (DCC) or in $\mathrm{E}_{2}$-containing medium. c-Myc levels are presented relative to those obtained in control siRNA cells cultivated in DCC (mean \pm S.E.M., $n=3$ ). The example of the blots includes also ER $\alpha$ protein showing that the transfection of siRNA for $c-M y c$ did not affect $E R \alpha$ function. As expected $E R \alpha$ levels decreased upon $E_{2}$ stimulation in the cells transfected with siRNA for c-Myc and in the siRNA control cells. (B) VEGF mRNA expression levels of the same samples as in (A). The levels are presented relative to those obtained in control siRNA cells cultivated in DCC (mean \pm s.E.M., $n=3$ ) and showed that inhibition of c-Myc blocked the transcription of $E_{2}$-induced VEGF. (C) c-Myc level in cells treated with Tet (overnight) and Tet $+E_{2}(6 \mathrm{~h})$. The levels are presented relative to those in cells cultivated in DCC (mean \pm s.E.M., $n=3$ ). (D) VEGF mRNA expression levels of the same samples as in (C). The levels are presented relative to the levels in cells cultivated in DCC (mean \pm S.E.M., $n=3$ ). ${ }^{\star} P<0.05,{ }^{\star \star} P<0.01$.

levels and hence, high expression level of c-Myc is necessary but not sufficient for the transient induction of VEGF transcription by estrogen.

\section{Co-binding of ER $\alpha$ and c-Myc on the VEGF promoter}

Estrogen stimulation in MCF7 cells was previously shown to enhance the interaction between ER $\alpha$ and c-Myc on ER $\alpha$ responsive promoters (Cheng et al. 2006). This finding and our above results led us to test whether c-Myc and ER $\alpha$ could bind together on the VEGF promoter. Following sequence analysis of the VEGF promoter, in which we searched for an ER $\alpha$ binding domain in proximity to a c-Myc binding domain, we found a putative variant ERE AATCAGACTGACT (three mismatches; two and one), $1.5 \mathrm{~kb}$ upstream of the transcription start site (TSS), in proximity (31 bp) to a c-Myc non-Ebox CAGCTG binding domain (Fig. 3A). Binding of ER $\alpha$ and c-Myc was then tested by ChIP and ChIP Re-IP, followed by PCR. 


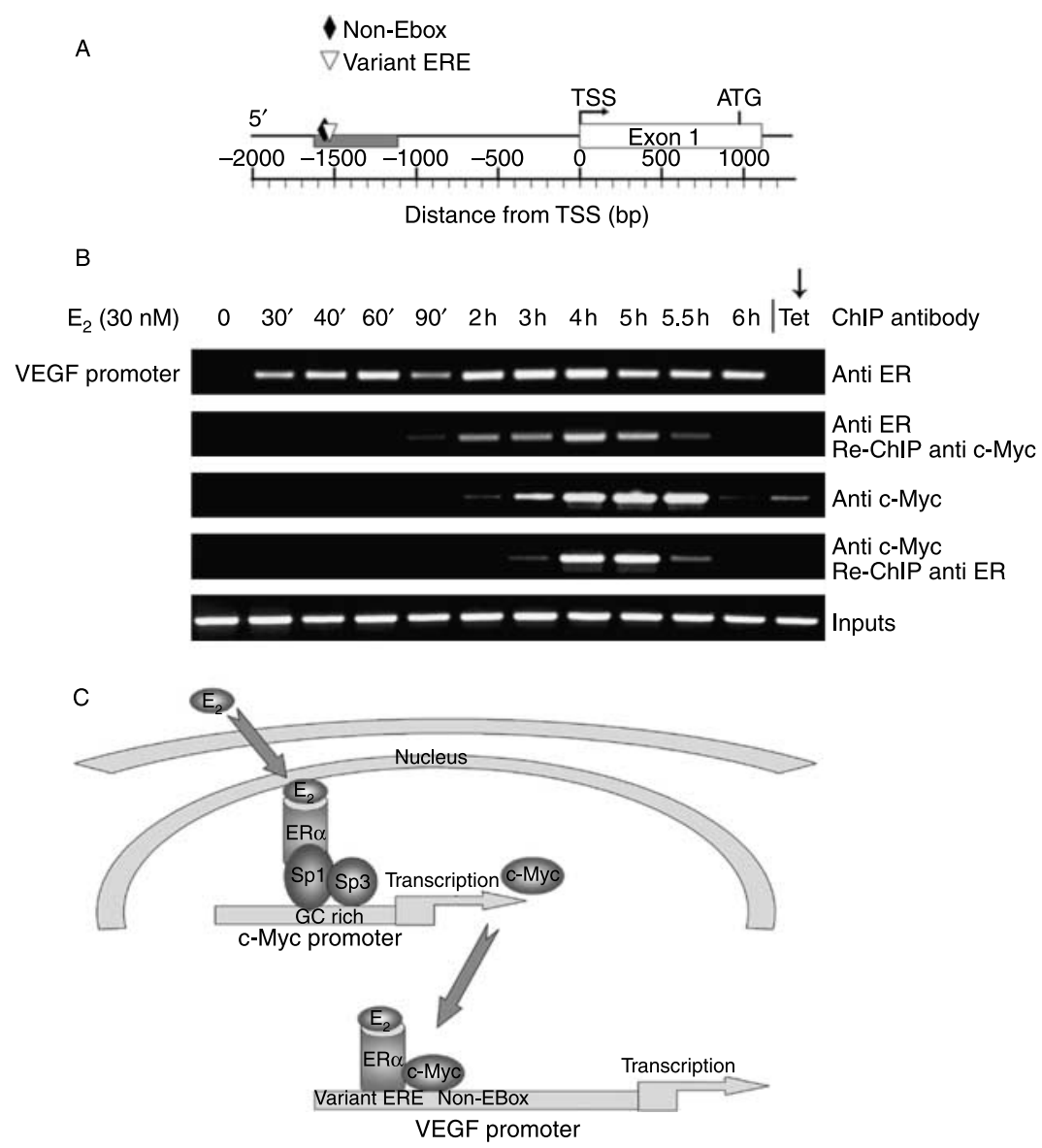

Figure 3 Co-recruitment of c-Myc and ER $\alpha$ to the VEGF promoter in response to the estrogen treatment. (A) Schematic diagram of the VEGF promoter, showing the locations of the amplicon, the variant ERE motifs, and the non-Ebox motifs. (B) Time course of estrogen-induced association of ER $\alpha$ and c-Myc with the VEGF promoter: the association was determined by ChIP and ChIP Re-IP. Inputs represent soluble chromatin that was amplified by PCR. (C) Schematic model illustrating the proposed mechanism underlying estrogen induction of VEGF mediated by c-Myc. Estrogen stimulates c-Myc transcription through recruitment of Sp proteins to the c-Myc promoter (Safe \& Kim 2004). Our findings show that c-Myc and $E_{2}$-activated ER $\alpha$ bind in close proximity to the VEGF promoter at $1.5 \mathrm{~kb}$ upstream of the transcription start site.

The results of the ChIP assay demonstrated that ER $\alpha$ and c-Myc each associates with VEGF promoter, with $\mathrm{ER} \alpha$ association ranging between 0.5 and $6 \mathrm{~h}$ and c-Myc association between 2 and $5.5 \mathrm{~h}$ after $\mathrm{E}_{2}$ administration (Fig. 3B, rows 1 and 3). Association of both $\mathrm{ER} \alpha$ and c-Myc was demonstrated to occur between 1.5 and $5.5 \mathrm{~h}$ after $\mathrm{E}_{2}$ administration (Fig. 3B, rows 2 and 4), with maximal binding at about 4-5 h. Overall, the binding of ER $\alpha$ and c-Myc to the VEGF promoter occurred within the time frame of the transient induction of VEGF mRNA (1-6 h; Fig. 1A).

Tet-induced overexpression of c-Myc alone resulted in its low level of binding to the VEGF promoter, however, in the absence of $E_{2}$, no binding of $E R \alpha$ to the c-Myc-VEGF promoter complex was detected (Fig. 3B, see arrow), neither induction of VEGF
mRNA (Fig. 2D). These results demonstrate that both $E_{2}$-activated $E R \alpha$ and $c-M y c$ bind the same complex on the VEGF promoter. A schematic illustration of a proposed mechanism underlying the cascade of events that leads to estrogen regulation of VEGF via $\mathrm{ER} \alpha$ and c-Myc is shown in Fig. 3C.

\section{Long-term estrogen regulation of VEGF mRNA and the effect of hypoxia in vitro}

The experimental conditions and hormonal treatment protocols in standard in vitro studies are very different from those in standard in vivo studies, and hence, correlation between the in vitro and in vivo results is not straightforward. Cells in vitro are cultured in estrogen-free medium and acute-estrogen treatment is applied, inducing a transient change monitored usually 
for a short term $(0.5-24 \mathrm{~h})$. Cells in tumors in vivo are chronically treated with estrogen during their growth and progression, over long times (days-to-weeks). The tumor cells are continuously under estrogen treatment and investigation of estrogen regulation involves estrogen withdrawal and monitoring the effects of withdrawal for a long term (days-to-weeks). In order to better mimic the in vivo conditions we have designed non-standard in vitro protocols: the cells were cultivated for 2 days in the presence of estrogen and then divided to three groups (EWD, $\mathrm{E}_{2}$, and Tet) as described in Materials and methods. Similar results were obtained for estrogen regulation of the expression levels of VEGF, c-Myc and ER $\alpha$ on the various days of treatment ( $3,4,5$ and $7 ; n=2$ per day). Consequently, the final results were summarized together as demonstrated in Fig. $4(n=8)$.

$\mathrm{E}_{2}$ long term treatment resulted in a stable and significant induction of VEGF relative to the level in cells treated in DCC medium (1.9 \pm 0.1 -fold increase, $P<0.01$; Fig. 4A). Furthermore, long-term Tet treatment of the cells that caused elevation in c-Myc also showed a significant increase in VEGF-mRNA as compared with cells cultured in DCC medium (1.5 \pm 0.2 -fold, $P<0.05$; Fig. 4A). Sustained estrogen treatment also resulted in a persistent and significant (1.5-fold) increase in the levels of c-Myc (Fig. 4B). As expected, the level of $\mathrm{ER} \alpha$ was lower under the influence of sustained $\mathrm{E}_{2}$ treatment as compared with that found in cells cultivated in DCC medium (Fig. 4C). Overall, the long-term effect of estrogen resulted in increased stable expression levels of c-Myc and VEGF mRNA, and decreased stable level of ER $\alpha$ relative to the levels in cells treated in DCC medium, however, the changes were about 2-fold lower than those reached during the transient $\mathrm{E}_{2}$ induction of the cells (Fig. 1).

In order to mimic possible in vivo stress conditions that can occur in tumors, we also investigated the influence of hypoxic, as compared to normoxic conditions on VEGF, c-Myc and ER $\alpha$ levels. Cells cultivated for 4 days in the three treatment groups (EWD, $\mathrm{E}_{2}$, and Tet) were subjected to either hypoxic or normoxic conditions for $14 \mathrm{~h}$. Hypoxic conditions induced a marked 4-fold increase in VEGF mRNA in cells cultivated in the presence or absence of $E_{2}$ as compared with the levels in EWD under normoxic conditions $(P<0.01 ;$ Fig. $5 \mathrm{~A})$. Similar to the long-term $\mathrm{E}_{2}$ treatment studies described above (see Fig. 4A), the level of VEGF mRNA in $E_{2}$-treated cells, relative to cells grown in EWD, both under normoxic conditions, was only 2 -fold higher $(2.0 \pm 0.3$-fold, $P<0.05$; Fig. 5A). The hypoxic conditions did not affect c-Myc level and did not interfere with the induction
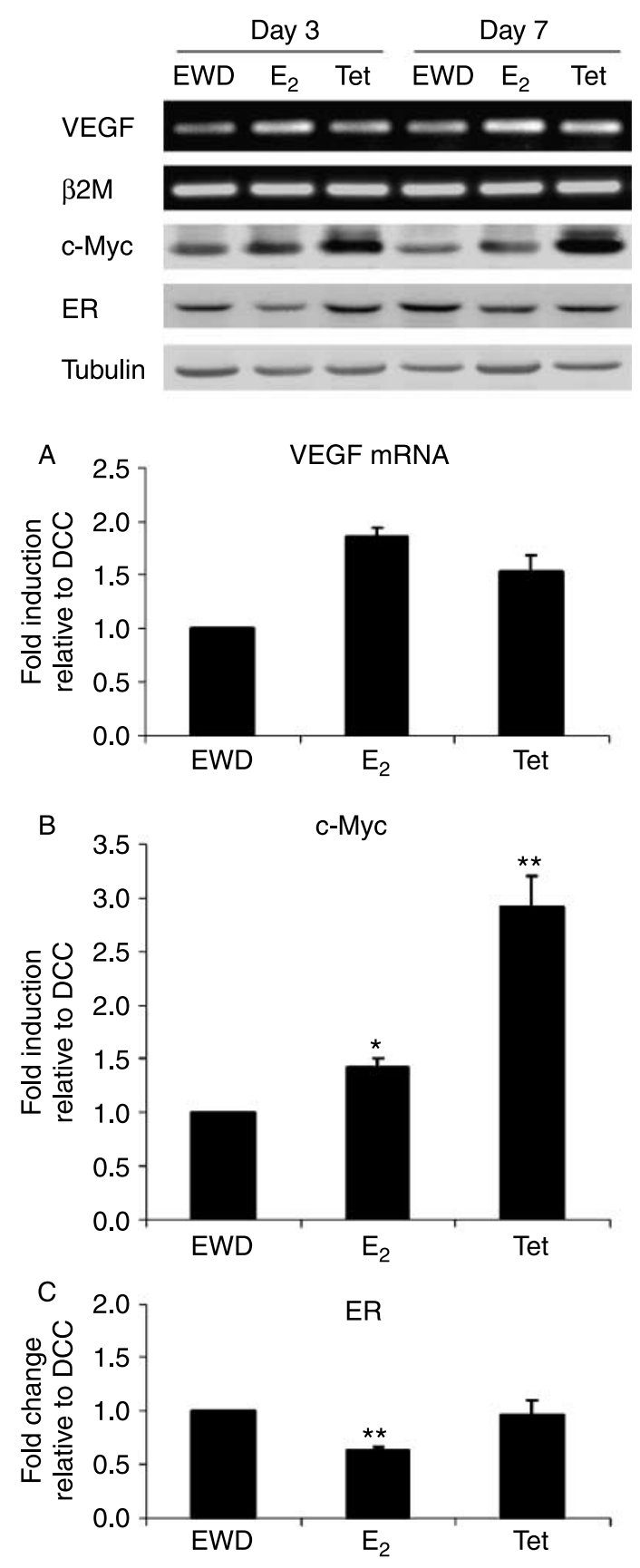

Figure 4 Long-term estrogen regulation of VEGF, c-Myc and $E R \alpha$ in MCF7-35im cells in vitro. (A) VEGF mRNA levels. (B) c-Myc protein expression levels of the same cells as in (A). (C) ER $\alpha$ protein expression levels of the same cells as in (A). Cells were initially cultivated in the presence of $E_{2}$ for 2 days and then divided to three groups: 1) $E_{2}$ withdrawal (EWD), 2) $E_{2}$ supplemented $\left(E_{2}\right)$, and 3$) E_{2}$ withdrawal + Tet (Tet). Cells in each group were harvested and analyzed after 3, 4, 5 and 7 days ( $n=2$ per each day). No significant differences in the results were found between the various days for the same treatment and hence, the results are summarized as the mean \pm S.E.M. fold change relative to cells in EWD $(n=8)$. ${ }^{\star} P<0.05,{ }^{* *} P<0.01$. 

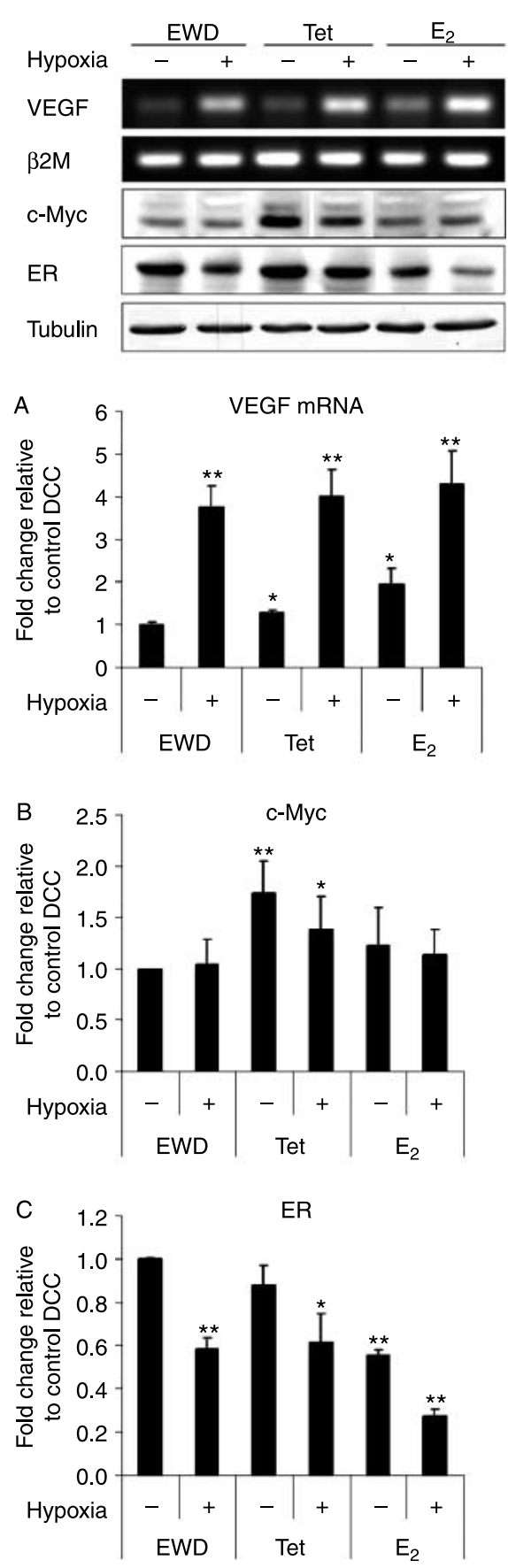

Figure 5 Induction of VEGF by hypoxia. Cells were cultivated for 2 days in DCC supplemented with $E_{2}$ and then divided into three groups: EWD, $E_{2}$, and Tet medium and cultivated for 4 days. The cells in each group were then incubated under hypoxic (+ hypoxia) or normoxic ( - hypoxia) conditions for $14 \mathrm{~h}$ before their harvest. (A) VEGF levels under the three treatment protocols with and without hypoxia. (B) c-Myc protein expression levels under the same treatments as described in A. (C) ER $\alpha$ protein expression levels under the same treatments as described in A. Results are presented as mean \pm S.E.M. $(n=3)$ fold change relative to those obtained in DCC ( - hypoxia). ${ }^{*} P<0.05,{ }^{\star \star} P<0.01$. of c-Myc by Tet; but due to experimental variations, the moderate long-term $\mathrm{E}_{2}$ induction of $\mathrm{c}-\mathrm{Myc}$ under normoxic conditions (1.5-fold as shown in Fig. 4B) was not significant in this particular set of experiments (Fig. 5B). However, hypoxia did reduce ER $\alpha$ level in cells cultivated in EWD and Tet medium, as well as in cells treated in $\mathrm{E}_{2}$ medium (Fig. 5C), in accord with the finding of Stoner et al. (2002).

Overall, we showed that hypoxic conditions induces VEGF mRNA expression more than 2-fold above the level induced by long-term $E_{2}$ treatment under normoxic conditions, dominating the expression level of VEGF. These results predict an increase in the expression of VEGF mRNA when the conditions maintained under $E_{2}$ regulation are replaced by hypoxic conditions.

\section{Estrogen regulation of VEGF and vascular function in vivo}

To investigate the in vivo regulation of VEGF by $\mathrm{E}_{2}$ and the involvement of c-Myc in this pathway, MCF7-35im cells were inoculated into the mammary fat pad of immunodeficient mice. Palpable solid tumors were developed within 3 weeks (median size $16 \mathrm{~mm}^{3}$ ) and then the mice were randomly divided into three treatment groups (see Materials and methods): $\mathrm{E}_{2}$, EWD and Tet-treated (Tet) mice. The vascular function of the tumors was investigated in vivo by MRI during 20 days of treatment. VEGF level, capillary density and $\mathrm{ER} \alpha$ level were measured ex vivo by immunohistochemistry at the end of the experiments.

All three treatment groups expressed considerable cytoplasmic VEGF levels (VEGF-121 + VEGF-165; Fig. 6). The VEGF levels after $E_{2}$ withdrawal were significantly higher than those in the $E_{2}$ group $(P<0.01, n=6$ in each group; Fig. 6B), suggesting that deregulation following $\mathrm{E}_{2}$ withdrawal led to a change in the microenvironmental conditions, such as increased hypoxia, and consequently upregulating VEGF expression (Fig. 6B). Withdrawal of $E_{2}$ but increased c-Myc activity in the Tet-treated group led to an intermediate VEGF level between the $\mathrm{E}_{2}$ and EWD tumors suggesting an alternative long-term regulation of VEGF by c-Myc. Measurements of VEGF-mRNA using in situ hybridization (Supplementary Figure 1, which can be viewed online at http:// erc.endocrinology-journals.org/supplemental/) failed to provide statistically significant results due to high inter- and intra-tumor heterogeneity.

$\mathrm{ER} \alpha$ immunostaining yielded quantitative results showing different levels for the three groups (Fig. 6). The lower level of $\mathrm{ER} \alpha$ in $\mathrm{E}_{2}$ treated tumors as 
A
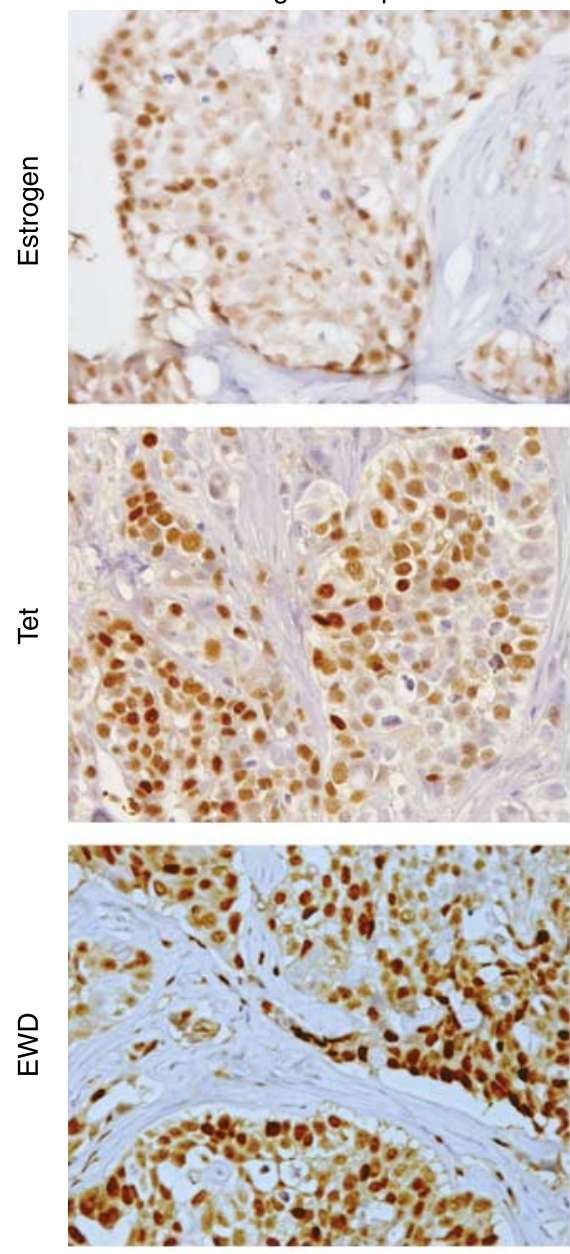

B

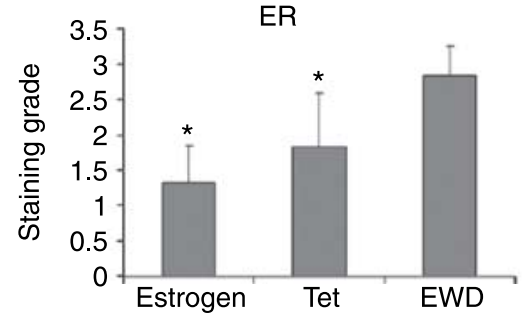

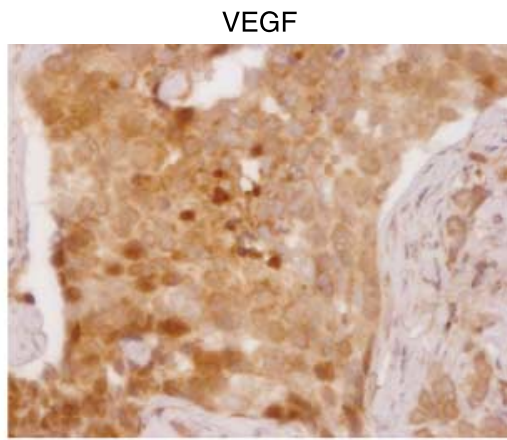
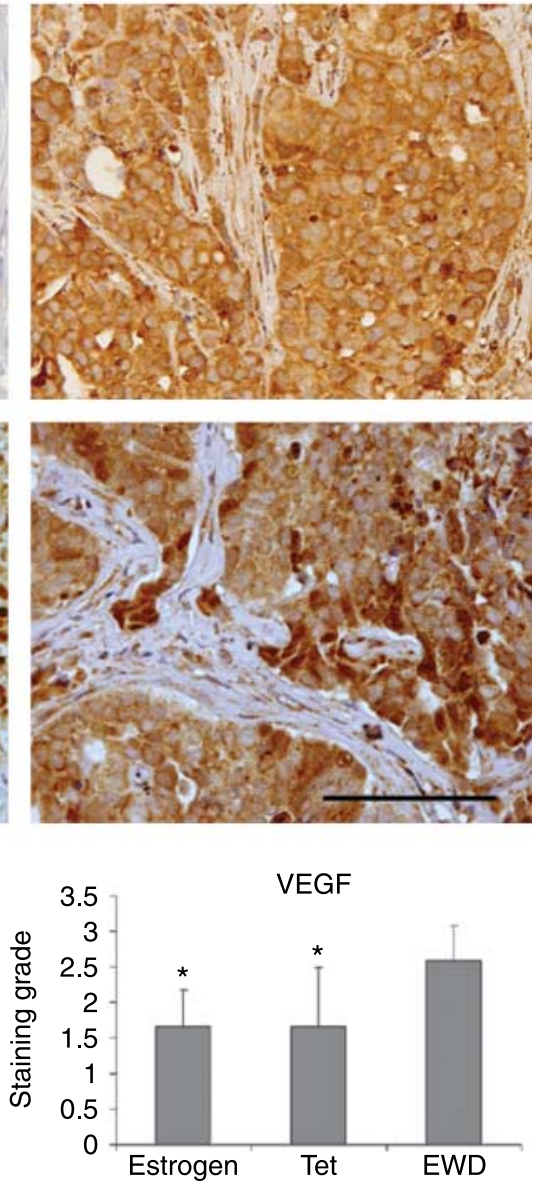

Figure 6 Estrogen effects on the expression of ER $\alpha$ and VEGF proteins in MCF7-35im tumor sections. (A) Expression levels of ER $\alpha$ (left) and VEGF (right) obtained by immunohistochemistry of serial tumor sections from three treatment groups: estrogen withdrawal (EWD), estrogen-supplemented and tetracycline (Tet) treated. Scale bar, $100 \mu \mathrm{m}$. (B) Quantification of the immunohistochemistry staining from the three treatment groups $(n=6),{ }^{*} P<0.05$.

compared to EWD tumors $(P<0.01, n=6$ in each group) served to indicate $\mathrm{E}_{2}$ activity through binding to $\mathrm{ER} \alpha$, which caused enhanced ER $\alpha$ degradation. The lower level of ER $\alpha$ in Tet-treated tumors indicated an effect of high c-Myc levels on ER $\alpha$ regulation. Unfortunately, immunostaining for c-Myc was only partially successful and did not allow for quantitative analysis.
The microcapillary density measured by immunostaining of endothelial cells for CD31 showed high variability within each tumor and did not differ significantly between the treatment groups (Supplementary Figure 2, which can be viewed online at http://erc.endocrinology-journals.org/supplemental/). However, non-invasive in vivo studies by means of dynamic contrast-enhanced (DCE)-MRI enabled us to 
detect significant differences in the vascular function among the three tumor groups. Analysis of the DCEMRI datasets yielded the influx ( $\left.K^{\text {trans }}\right)$ and efflux $\left(k_{\mathrm{ep}}\right)$ transcapillary transfer constants through the capillary walls. These transfer constants were shown to be dominated in MCF7 tumors by the product of the capillary permeability and surface area, termed permeability factor (Furman-Haran et al. 1997).

A representative, color-coded, $K^{\text {trans }}$ map superimposed on the morphological $\mathrm{T}_{2}$-weighted image from each treatment group is shown in Fig. 7A. The transcapillary transfer constants, $K^{\text {trans }}$ and $k_{\text {ep }}$, were found to be higher in the tumor tissue compared to the surrounding tissues $(3.4 \pm 0.6$-fold higher than in the muscle tissue). Notably, both transcapillary transfer constants, and hence the capillaries' permeability factor, were significantly higher in the EWD tumors as compared with $\mathrm{E}_{2}$ tumors $(P<0.01)$, in agreement with the higher VEGF in the EWD group. The transfer constants in the Tet-treated tumors were intermediate between the two other groups with $k_{\text {ep }}$ significantly lower than that in the EWD tumors $(P<0.05$; Fig. 7B). These results suggested lower permeability factors in these tumors in accordance with the measured VEGF levels in the Tet-induced tumors that overexpressed c-Myc alone (Fig. 6).

The non-invasive nature of the MRI experiments enabled us to sequentially monitor in the same tumor
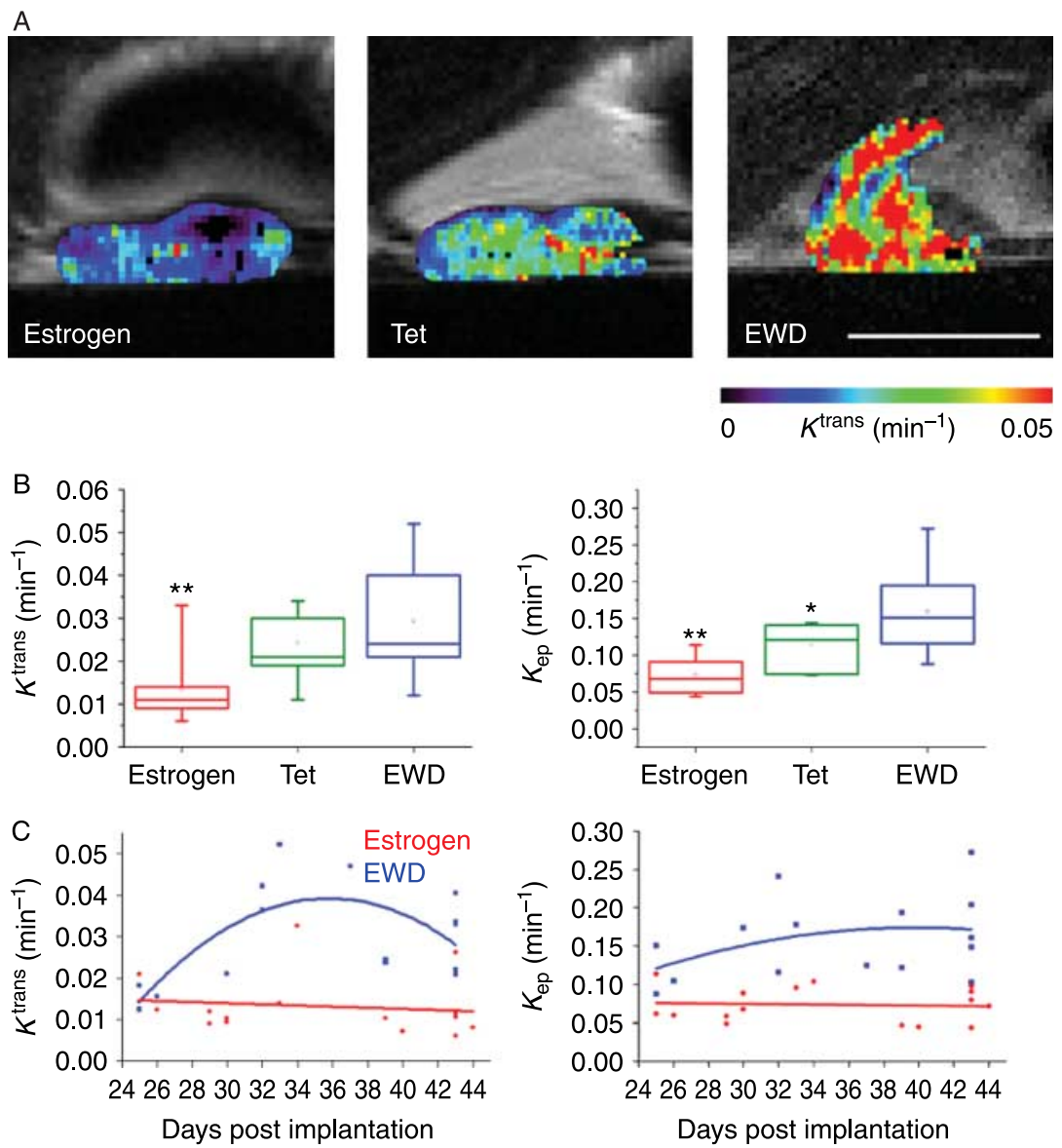

Figure 7 Estrogen effects on the microvascular function of the tumors. Tumors were monitored by imaging at 25 days post-inoculation. Data analysis yielded the influx transcapillary transfer constants $K^{\text {trans }}$, and the efflux transfer rate constant $k_{\mathrm{ep}}$. (A) Representative color-coded parametric maps of $K^{\text {trans }}$, superimposed onto the corresponding anatomical image ( $\mathrm{T}_{2}$-weighted) of a tumor slice in an estrogen-treated tumor, Tet-treated tumor, and estrogen withdrawn tumor (EWD) recorded 20 after treatment initiation. Scale bar $=5 \mathrm{~mm}$. (B) The mean of percentile values of $K^{\text {trans }}$ and $k_{\mathrm{ep}}$, for the three treatment groups: estrogen ( $\left.n=8\right)$, Tet $(n=5)$, and EWD $(n=7)$. For each box, the lower line represents the 25 percentile mean, the middle line the median mean, and the upper line the 75 percentile mean; statistical analysis was preformed using ANOVA, together with Dunnet's multiple comparison tests. Significant differences relative to the values in control tumors: ${ }^{\star} P<0.05,{ }^{*} P<0.01$. (C) Temporal changes in the median values per tumor of the transcapillary transfer constant, $K^{\text {trans }}$ and efflux trascapillary rate constant, $k_{\mathrm{ep}}$ for the estrogen and EWD groups described in A. Treatments were initiated on day 23-25 after implantation and continued up to day 45 after implantation. A fitted trend line is illustrating the pattern of dynamic changes in the transcapillary rate constants over time. 
changes in the transfer constants during 20 days of treatment. The transfer constants in the $\mathrm{E}_{2}$ treated tumors were found to be stable, at approximately similar values, throughout the 20 days of the monitoring (Fig. 7C), in agreement with the stable VEGF levels reached in vitro during long-term $\mathrm{E}_{2}$ treatment (Fig. 4C). Withdrawal of $\mathrm{E}_{2}$ caused an increase in both transfer constants within the first week (Fig. 7C), in accord with the high VEGF level in these tumors. The Tet tumors that sustained high c-Myc levels displayed over time intermediate transfer constant values between the two other groups (not shown) in accord with the intermediate VEGF levels in long term c-Myc upregulated cells in vitro, suggesting regulation of VEGF, and consequently vascular permeability, by c-Myc alone.

\section{Discussion}

Estrogen regulation of VEGF expression in vitro and in vivo and of vascular permeability in vivo has been investigated in MCF7 and MCF7-35im human breast cancer cells, specifically examining the role of c-Myc in this regulation. By investigating MCF7-35im, stably transfected with an inducible $c-M y c$, we were able to differentiate between the cooperative role of estrogen activated ER $\alpha$ and c-Myc and the role of c-Myc alone in the regulation of VEGF. The use of various protocols in vitro and the extension to in vivo studies illuminated differences stemming from variations in treatments and environmental conditions.

The results show that c-Myc participates with ER $\alpha$ in the estrogenic regulation of VEGF but also independently regulates VEGF levels and vascular permeability when overexpressed for long periods. Hence, in addition to the increased c-Myc-induced mitogenic capacity in antiestrogen resistant cells (Venditti et al. 2002, Doisneau-Sixou et al. 2003), c-Myc, may also enhance tumor progression by regulating VEGF levels and capillary permeability.

The novel mechanism by which estrogen regulates VEGF expression involves the co-binding of $E_{2}$ activated ER and c-Myc on a specific site of the VEGF promoter. As the VEGF core promoter does not contain a typical estrogen-responsive element (Loureiro \& D' Amore 2005), we searched for a variant ERE in proximity to the c-Myc-binding element on the VEGF promoter. A variant ERE, $1520 \mathrm{bp}$ upstream to the TSS, was located near a c-Myc-binding non-Ebox element. The same element on the VEGF promoter was previously shown to bind $\mathrm{ER} \alpha$ and to exhibit $\mathrm{E}_{2}$ responsiveness (Buteau-Lozano et al. 2002). Several estrogen-responsive regions were located on the VEGF promoter; however, only few were found to be functionally active (Hyder et al. 2000, Mueller et al. 2000). Alternatively, ER $\alpha$ and c-Myc may interact with SP proteins through binding to GC-rich motif on the VEGF promoter ( -66 to -47$)$ as was shown in ZR-75-1 cells (Stoner et al. 2004).

The co-binding of c-Myc and ER $\alpha$ on the VEGF promoter in MCF7 cells is in agreement with the previous prediction of Driscoll et al. (1998) that a variant ERE with three mismatches requires the binding of an additional protein for activation. Other ER-responsive promoters have been previously found to contain both ER and c-Myc binding elements located within close proximity to each other, suggesting that ER and c-Myc physically interact to stabilize the ER-coactivator complex (Cheng et al. 2006). However, we can not exclude that ER and c-Myc interact via bridging proteins, such as TRRAP (McMahon et al. 1998, Cole \& McMahon 1999). Another study revealed that a direct interaction between BRCA1 and ER regulates VEGF transcription and secretion (Kawai et al. 2002). Notably, estrogen has also been associated with HIF1 $\alpha$ regulation of VEGF, and induced recruitment of both ER and HIF1 $\alpha$ to the VEGF promoter in the rat uterus (Kazi et al. 2005). Thus, the co-binding of the activated ER with other transcription factors, to non-classical binding sites on gene promoters, appears to be a common mechanism underlying estrogen regulation of gene transcription.

ER $\beta$ may also have a role in the regulation of VEGF by estrogen and affect its transcription. Studies focusing on this mechanism were previously conducted using ER $\beta$ transfected MCF7 and MDA-MB-231 breast cancer cells and transient transfection assays with the VEGF $(-2275 /+54)$ promoter-luciferase construct (Buteau-Lozano et al. 2002). The results indicated different transactivational mechanisms between the two ERs and suggested that heterodimerization of $\mathrm{ER} \alpha / \mathrm{ER} \beta$ may inhibit estrogeninduced VEGF expression. Another study showed that ER $\beta$ exerts an inhibitory effect on VEGF transcription in T47D breast cancer cells (Hartman et al. 2006). A recent genome-wide study (Williams et al. 2008, oncogene) showed that the ER $\beta$ overexpression had a repressive effect on most ER $\alpha$-induced genes. MCF7 cells predominantly express ER $\alpha$ (Shaw et al. 2006) but the low expression of ER $\beta$ may also affect estrogen regulation of VEGF. We have found that knockdown of ER $\beta$ in these cells did not alter estrogen induction of VEGF mRNA and of c-Myc, neither estrogen reduction of $\mathrm{ER} \alpha$ levels. These results indicate that estrogen regulation of VEGF in cells with a 
predominance of $E R \alpha$ is not affected significantly by $E R \beta$, although we can not exclude a role for $\operatorname{ER} \beta$ in cells with high expression levels of this receptor.

It has been shown that ER $\alpha$ and c-Myc levels are high in a large fraction of breast cancers and that both transcription factors are upregulated in ER-positive human breast cancer cell lines (Butt et al. 2008). It is, therefore, reasonable to hypothesize that $\mathrm{c}-\mathrm{Myc}$ involvement in the estrogen regulation of VEGF may occur in a significant fraction of breast cancers. To prove this hypothesis it is necessary to further characterize estrogen regulation of VEGF in biopsies of breast cancer patients and in cancer cells and tumors in animal models. Further studies in this direction are currently underway; in preliminary experiments we found that the time course of estrogen stimulation of c-Myc in ZR-75-1 human breast cancer cells is similar to that in MCF7 cells (unpublished results) and parallels the time course of VEGF induction in these cells, also reported by Stoner et al. (2004).

When comparing the effects of estrogen treatment in vitro and in vivo, a disparity between the findings is expected due to several reasons. First, environmental conditions of cultured cells are different from those in tumors. In cultures, the conditions are well-controlled with time, whereas in tumors the conditions are invariably modulated with time, depending on the microvasculature perfusion efficiency. We indeed have chosen MCF7 cells for our studies, as these extensively investigated ER-positive cells develop tumors within a reasonable time frame without the need to use additives (such as matrigel) that could further modulate angiogenesis and tumor perfusion. We also monitored the tumors when they were small, minimizing the development of necrosis and of treatment-independent fluctuations in microenvironmental conditions that usually occur in large, fast-growing tumors.
Second, the in vitro and in vivo systems dictate different experimental designs of hormonal manipulation. Standard estrogen manipulation of cancer cells in vitro starts from conditions of estrogen deprivation, followed by estrogen administration, whereas in implanted tumors, estrogen must be provided for the tumors' growth and estrogen manipulation starts by $\mathrm{E}_{2}$ withdrawal. These two types of hormonal manipulations are not comparable, or symmetric, as the in vitro manipulation evokes a regulation process and the in vivo manipulation initiates a deregulation process.

The third factor is related to the time course of the estrogenic effect; the single estrogen treatment in vitro induces transient changes in gene expression levels, whereas the long-term estrogen treatment, in vitro or in vivo, induces sustained gene expression levels. The extent of the sustained VEGF and c-Myc inductions, and of $E R \alpha$ reductions, during the long-term treatment of the cells in vitro, were moderate as compared to the extent of the corresponding changes during the transient induction. This phenomenon represents estrogen regulation of a steady gene expression state that simulates better the physiological conditions in the in vivo studies than the transient regulation. These results are in line with previous studies comparing in vitro and in vivo regulation of genes by estrogen, showing that fold changes observed in vitro greatly exceed those measured in vivo (Harvell et al. 2006).

Our experimental models are, therefore, complementary and the differences between the results in vitro and in vivo stem from the above-mentioned disparities in the experimental protocols rather than from a discrepancy between the intrinsic responses of the cells. Indeed, differences between in vivo and in vitro estrogen-induced changes in gene expression were previously demonstrated in other investigations (Creighton et al. 2006, Harvell et al. 2006).
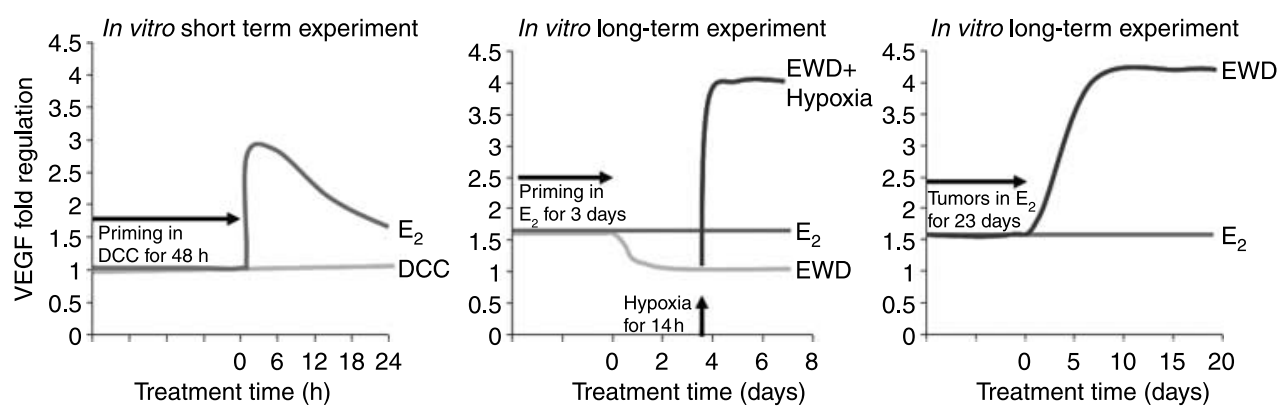

Figure 8 A schematic drawing of estrogen regulation of VEGF expression in in vitro and in vivo experiments. Left: short term, transient estrogen-induced changes in VEGF expression level in vitro. Middle: long-term estrogen regulation of VEGF expression levels and changes induced by estrogen withdrawal (EWD) and under hypoxia in vitro. Right: long-term estrogen regulation of VEGF levels and deregulation following EWD in vivo. 
$\mathrm{E}_{2}$ treatment of the tumors over 20 days resulted in sustained levels of VEGF and maintained stable and low capillary permeability, whereas $\mathrm{E}_{2}$-withdrawal led to an increase in the level of VEGF expression and of the capillary permeability, presumably due to increased hypoxic conditions. Similar increased VEGF level and capillary permeability were previously detected in MCF7 tumors upon tamoxifen treatment (Furman-Haran et al. 1997, Bogin \& Degani 2002). These in vivo results are also in agreement with those obtained in vitro, under long-term estrogen regulation of VEGF, and as a results of hypoxic conditions (Scott et al. 1998, Maity et al. 2001). Further supportive evidence for the induction of VEGF by hypoxia in EWD MCF7 tumors were provided by the study of Evans et al. (1997), showing that treatment of MCF7 tumors with tamoxifen resulted in increased hypoxia as compared with $\mathrm{E}_{2}$-supplemented tumors.

A schematic drawing (Fig. 8) based on our results shows the difference between the temporal modulations in VEGF expression levels during short term estrogen transient induction and long term estrogen treatment, followed by estrogen withdrawal and hypoxia, in vitro, as well as in tumors, in vivo, under long term estrogen treatment and after estrogen withdrawal. The similarity in the induction of VEGF after estrogen withdrawal + hypoxic conditions in long term $\mathrm{E}_{2}$-treated cells and after estrogen withdrawal in tumors in vivo supports the hypothesis that estrogen withdrawal in tumors induces hypoxic conditions responsible for VEGF upregulation. We, therefore, suggest that in tumors under $E_{2}$, hypoxia is less likely to develop, as VEGF levels are regulated at a stable level that allows angiogenesis, and the formation of well functioning blood capillaries, supporting tumor progression. After $\mathrm{E}_{2}$ withdrawal, deregulation of VEGF and other $E_{2}$ regulated genes modify angiogenesis. This sequence of events leads to regional hypoxic conditions, which markedly induce VEGF expression, thereby increasing capillary permeability. The above events after $E_{2}$ withdrawal are not instantaneous and uniform for all tumors and occur within several days after $\mathrm{E}_{2}$ withdrawal (Fig. 7C).

In summary, we discovered a novel mechanism by which estrogen regulates VEGF expression in breast cancer cells, involving ER $\alpha$ activation of c-Myc and the co-binding of $\mathrm{E}_{2}$-activated $\mathrm{ER} \alpha$ and $\mathrm{c}-\mathrm{Myc}$ on the VEGF promoter. The results clearly showed that transient $E_{2}$ induction of VEGF depends on $E_{2}$-induced upregulation of c-Myc. Long-term treatment with $\mathrm{E}_{2}$, as well as long-term upregulation of c-Myc induced a smaller increase in the level of VEGF as compared to the transient induction but regulated steady gene expression levels. The results also revealed the disparity between the transient in vitro regulation and the chronic in vivo regulation, highlighting the complexity of $E_{2}$ regulation in the unstable microenvironment of tumors. Investigating the effects of hypoxic conditions in vitro served to explain this disparity and suggested a sequence of events that provided a complemented picture of estrogen regulation of VEGF.

\section{Declaration of interest}

The authors declare that there is no conflict of interest that would prejudice the impartiality of this scientific work.

\section{Funding}

This work was supported by grants from the National Institutes of Health, USA (CA 422238), the Israel Science Foundation (801/04 and 235/08), and by the Mario Negri Institute - Weizmann Institute collaboration grant.

\section{Acknowledgements}

We are very grateful to Prof. Robert P Shiu, University of Manitoba, Winnipeg, Canada, for providing us MCF7-35im cells and guiding us in their use. We thank Dr Adi Yosepovich, Dr Tamara Berkutzki, Dr Shifra Ben-Dor, Ms Amanda Feuerstein for their help in the course of this study and Ms Barbara Morgenstern for the manuscript editing. Hadassa Degani is the incumbent of the Fred and Andrea Fallek Professorial Chair for Breast Cancer Research.

\section{References}

Barr LF, Campbell SE, Diette GB, Gabrielson EW, Kim S, Shim H \& Dang CV 2000 c-Myc suppresses the tumorigenicity of lung cancer cells and down-regulates vascular endothelial growth factor expression. Cancer Research 60 143-149.

Baudino TA, McKay C, Pendeville-Samain H, Nilsson JA, Maclean KH, White EL, Davis AC, Ihle JN \& Cleveland JL 2002 c-Myc is essential for vasculogenesis and angiogenesis during development and tumor progression. Genes and Development 16 2530-2543.

Bogin L \& Degani H 2002 Hormonal regulation of VEGF in orthotopic MCF7 human breast cancer. Cancer Research 62 1948-1951.

Buteau-Lozano H, Ancelin M, Lardeux B, Milanini J \& Perrot-Applanat M 2002 Transcriptional regulation of vascular endothelial growth factor by estradiol and tamoxifen in breast cancer cells: a complex interplay between estrogen receptors alpha and beta. Cancer Research 62 4977-4984.

Butt AJ, Caldon CE, McNeil CM, Swarbrick A, Musgrove EA \& Sutherland RL 2008 Cell cycle 
machinery: links with genesis and treatment of breast cancer. Advances in Experimental Medicine and Biology 630 189-205.

Cheng AS, Jin VX, Fan M, Smith LT, Liyanarachchi S, Yan PS, Leu YW, Chan MW, Plass C, Nephew KP et al. 2006 Combinatorial analysis of transcription factor partners reveals recruitment of c-MYC to estrogen receptor-alpha responsive promoters. Molecular Cell 21 393-404.

Cole MD \& McMahon SB 1999 The Myc oncoprotein: a critical evaluation of transactivation and target gene regulation. Oncogene 18 2916-2924.

Creighton CJ, Cordero KE, Larios JM, Miller RS, Johnson MD, Chinnaiyan AM, Lippman ME \& Rae JM 2006 Genes regulated by estrogen in breast tumor cells in vitro are similarly regulated in vivo in tumor xenografts and human breast tumors. Genome Biology 7 R28.

Dang CV, Resar LM, Emison E, Kim S, Li Q, Prescott JE, Wonsey D \& Zeller K 1999 Function of the c-Myc oncogenic transcription factor. Experimental Cell Research 253 63-77.

Doisneau-Sixou SF, Sergio CM, Carroll JS, Hui R, Musgrove EA \& Sutherland RL 2003 Estrogen and antiestrogen regulation of cell cycle progression in breast cancer cells. Endocrine-Related Cancer 10 179-186.

Driscoll MD, Sathya G, Muyan M, Klinge CM, Hilf R \& Bambara RA 1998 Sequence requirements for estrogen receptor binding to estrogen response elements. Journal of Biological Chemistry 273 29321-29330.

Dubik D \& Shiu RP 1988 Transcriptional regulation of c-myc oncogene expression by estrogen in hormone-responsive human breast cancer cells. Journal of Biological Chemistry 263 12705-12708.

Dubik D \& Shiu RP 1992 Mechanism of estrogen activation of c-myc oncogene expression. Oncogene 7 1587-1594.

Dvorak HF 2002 Vascular permeability factor/vascular endothelial growth factor: a critical cytokine in tumor angiogenesis and a potential target for diagnosis and therapy. Journal of Clinical Oncology 20 4368-4380.

Evans SM, Koch CJ, Laughlin KM, Jenkins WT, Van Winkle T \& Wilson DF 1997 Tamoxifen induces hypoxia in MCF-7 xenografts. Cancer Research 57 5155-5161.

Frasor J, Danes JM, Komm B, Chang KC, Lyttle CR \& Katzenellenbogen BS 2003 Profiling of estrogen up- and down-regulated gene expression in human breast cancer cells: insights into gene networks and pathways underlying estrogenic control of proliferation and cell phenotype. Endocrinology $1444562-4574$.

Furman-Haran E, Grobgeld D \& Degani H 1997 Dynamic contrast-enhanced imaging and analysis at high spatial resolution of MCF7 human breast tumors. Journal of Magnetic Resonance 128 161-171.

Hartman J, Lindberg K, Morani A, Inzunza J, Strom A \& Gustafsson JA 2006 Estrogen receptor beta inhibits angiogenesis and growth of T47D breast cancer xenografts. Cancer Research 66 11207-11213.
Harvell DM, Richer JK, Allred DC, Sartorius CA \& Horwitz KB 2006 Estradiol regulates different genes in human breast tumor xenografts compared with the identical cells in culture. Endocrinology 147 700-713 (Epub 2005 Oct 2020).

Hicklin DJ \& Ellis LM 2005 Role of the vascular endothelial growth factor pathway in tumor growth and angiogenesis. Journal of Clinical Oncology 23 1011-1027.

Hyder SM 2006 Sex-steroid regulation of vascular endothelial growth factor in breast cancer. Endocrine-Related Cancer 13 667-687.

Hyder SM, Nawaz Z, Chiappetta C \& Stancel GM 2000 Identification of functional estrogen response elements in the gene coding for the potent angiogenic factor vascular endothelial growth factor. Cancer Research 60 3183-3190.

Jarvinen TA, Pelto-Huikko M, Holli K \& Isola J 2000 Estrogen receptor beta is coexpressed with ERalpha and PR and associated with nodal status, grade, and proliferation rate in breast cancer. American Journal of Pathology 156 29-35.

Kawai H, Li H, Chun P, Avraham S \& Avraham HK 2002 Direct interaction between BRCA1 and the estrogen receptor regulates vascular endothelial growth factor (VEGF) transcription and secretion in breast cancer cells. Oncogene 21 7730-7739.

Kazi AA, Jones JM \& Koos RD 2005 Chromatin immunoprecipitation analysis of gene expression in the rat uterus in vivo: estrogen-induced recruitment of both estrogen receptor alpha and hypoxia-inducible factor 1 to the vascular endothelial growth factor promoter. Molecular Endocrinology 19 2006-2019.

Knies-Bamforth UE, Fox SB, Poulsom R, Evan GI \& Harris AL 2004 c-Myc interacts with hypoxia to induce angiogenesis in vivo by a vascular endothelial growth factor-dependent mechanism. Cancer Research 64 6563-6570.

Kurebayashi J, Otsuki T, Kunisue H, Tanaka K, Yamamoto S \& Sonoo H 2000 Expression levels of estrogen receptoralpha, estrogen receptor-beta, coactivators, and corepressors in breast cancer. Clinical Cancer Research 6 512-518.

Liao DJ \& Dickson RB 2000 c-Myc in breast cancer. Endocrine-Related Cancer 7 143-164.

Long X \& Nephew KP 2006 Fulvestrant (ICI 182,780)dependent interacting proteins mediate immobilization and degradation of estrogen receptor-alpha. Journal of Biological Chemistry 281 9607-9615.

Loureiro RM \& D'Amore PA 2005 Transcriptional regulation of vascular endothelial growth factor in cancer. Cytokine \& Growth Factor Reviews 16 77-89.

Maity A, Sall W, Koch CJ, Oprysko PR \& Evans SM 2001 Low $\mathrm{pO}_{2}$ and beta-estradiol induce VEGF in MCF-7 and MCF-7-5C cells: relationship to in vivo hypoxia. Breast Cancer Research and Treatment 67 51-60. 
McMahon SB, Van Buskirk HA, Dugan KA, Copeland TD \& Cole MD 1998 The novel ATM-related protein TRRAP is an essential cofactor for the c-Myc and E2F oncoproteins. Cell 94 363-374.

Mueller MD, Vigne JL, Minchenko A, Lebovic DI, Leitman DC \& Taylor RN 2000 Regulation of vascular endothelial growth factor (VEGF) gene transcription by estrogen receptors alpha and beta. PNAS 97 10972-10977.

Musgrove EA, Sergio CM, Loi S, Inman CK, Anderson LR, Alles MC, Pinese M, Caldon CE, Schutte J, GardinerGarden M et al. 2008 Identification of functional networks of estrogen- and c-Myc-responsive genes and their relationship to response to tamoxifen therapy in breast cancer. PLOS ONE 3 e2987.

Nilsson S, Makela S, Treuter E, Tujague M, Thomsen J, Andersson G, Enmark E, Pettersson K, Warner M \& Gustafsson JA 2001 Mechanisms of estrogen action. Physiological Reviews 81 1535-1565.

Palmieri C, Cheng GJ, Saji S, Zelada-Hedman M, Warri A, Weihua Z, Van Noorden S, Wahlstrom T, Coombes RC, Warner M et al. 2002 Estrogen receptor beta in breast cancer. Endocrine-Related Cancer 9 1-13.

Pelengaris S, Khan M \& Evan G 2002 c-MYC: more than just a matter of life and death. Nature Reviews. Cancer 2 764-776.

Prall OW, Rogan EM, Musgrove EA, Watts CK \& Sutherland RL 1998 c-Myc or cyclin D1 mimics estrogen effects on cyclin E-Cdk2 activation and cell cycle reentry. Molecular and Cellular Biology 18 4499-4508.

Reid G, Hubner MR, Metivier R, Brand H, Denger S, Manu D, Beaudouin J, Ellenberg J \& Gannon F 2003 Cyclic, proteasome-mediated turnover of unliganded and liganded ERalpha on responsive promoters is an integral feature of estrogen signaling. Molecular Cell 11 695-707.

Ruohola JK, Valve EM, Karkkainen MJ, Joukov V, Alitalo K \& Harkonen PL 1999 Vascular endothelial growth factors are differentially regulated by steroid hormones and antiestrogens in breast cancer cells. Molecular Endocrinology 149 29-40.

Safe S \& Kim K 2004 Nuclear receptor-mediated transactivation through interaction with $\mathrm{Sp}$ proteins. Progress in Nucleic Acid Research and Molecular Biology 77 1-36.

Scott PA, Gleadle JM, Bicknell R \& Harris AL 1998 Role of the hypoxia sensing system, acidity and reproductive hormones in the variability of vascular endothelial growth factor induction in human breast carcinoma cell lines. International Journal of Cancer 75 706-712.

Shang Y, Hu X, DiRenzo J, Lazar MA \& Brown M 2000 Cofactor dynamics and sufficiency in estrogen receptorregulated transcription. Cell 103 843-852.
Shaw LE, Sadler AJ, Pugazhendhi D \& Darbre PD 2006 Changes in oestrogen receptor-alpha and -beta during progression to acquired resistance to tamoxifen and fulvestrant (Faslodex, ICI 182,780) in MCF7 human breast cancer cells. Journal of Steroid Biochemistry and Molecular Biology 99 19-32.

Shchors K, Shchors E, Rostker F, Lawlor ER, Brown-Swigart L \& Evan GI 2006 The Myc-dependent angiogenic switch in tumors is mediated by interleukin 1beta. Genes and Development 20 2527-2538.

Stoner M, Saville B, Wormke M, Dean D, Burghardt R \& Safe S 2002 Hypoxia induces proteasome-dependent degradation of estrogen receptor alpha in ZR-75 breast cancer cells. Molecular Endocrinology 16 2231-2242.

Stoner M, Wormke M, Saville B, Samudio I, Qin C, Abdelrahim M \& Safe S 2004 Estrogen regulation of vascular endothelial growth factor gene expression in ZR-75 breast cancer cells through interaction of estrogen receptor alpha and SP proteins. Oncogene $\mathbf{2 3}$ 1052-1063.

Strom A, Hartman J, Foster JS, Kietz S, Wimalasena J \& Gustafsson JA 2004 Estrogen receptor beta inhibits 17beta-estradiol-stimulated proliferation of the breast cancer cell line T47D. PNAS $\mathbf{1 0 1}$ 1566-1571.

Takei H, Lee ES \& Jordan VC 2002 In vitro regulation of vascular endothelial growth factor by estrogens and antiestrogens in estrogen-receptor positive breast cancer. Breast Cancer 9 39-42.

Tofts PS 1997 Modeling tracer kinetics in dynamic Gd-DTPA MR imaging. Journal of Magnetic Resonance Imaging 7 91-101.

Tofts PS, Brix G, Buckley DL, Evelhoch JL, Henderson E, Knopp MV, Larsson HB, Lee TY, Mayr NA, Parker GJ et al. 1999 Estimating kinetic parameters from dynamic contrast-enhanced T(1)-weighted MRI of a diffusable tracer: standardized quantities and symbols. Journal of Magnetic Resonance Imaging 10 223-232.

Venditti M, Iwasiow B, Orr FW \& Shiu RP 2002 C-myc gene expression alone is sufficient to confer resistance to antiestrogen in human breast cancer cells. International Journal of Cancer 99 35-42.

Williams C, Edvardsson K, Lewandowski SA, Ström A \& Gustafsson JA 2008 A genome-wide study of the repressive effects of estrogen receptor beta on estrogen receptor alpha signaling in breast cancer cells. Oncogene 27 1019-1032.

Yancopoulos GD, Davis S, Gale NW, Rudge JS, Wiegand SJ \& Holash J 2000 Vascular-specific growth factors and blood vessel formation. Nature 407 242-248. 